\title{
Protein-ligand Binding Assay by Liquid Chromatography-Mass Spectrometry Xiyan Li
}

Department of Genetics, Stanford University, Stanford, USA

*For correspondence: lixiyan@stanford.edu

[Abstract] Protein-small molecule binding coefficients are determined by quantitative LC-MS in this method. Traditional biochemical plot is consequently used to set up the binding curve between a known protein and a small molecule $(<1,000 \mathrm{Da})$ to determine the affinity constant $(\mathrm{Kd})$ and the stoichiometry (Bmax).

\section{Materials and Reagents}

1. Purified protein (preferred in solution without any detergent like Tween, Triton, etc., concentration > $1 \mathrm{mM}$ )

2. Small molecule standard (best of highest available purity/grade, dissolved in the same solution used for proteins, in a 2-fold series of 10x desired concentration)

Note: To minimize organic solvent effect on binding, the stock solution has to be diluted in the same series in organic solvent first, and then mixed into the aqueous solution to make final standards.

3. Zeba spin desalting columns micro (Pierce Antibodies, catalog number: 89877 and 89878)

4. Methanol (mass spec grade)

\section{Equipment}

1. Microcentrifuge

2. Quantitative LC-MS (such as HPLC-coupled triple quad)

3. Eppendorf Protein LoBind tubes $(0.5 \mathrm{ml}$ and $1.5 \mathrm{ml})$

4. LCQuan software (Thermo Fisher Scientific)

\section{Procedure}

1. Load $200 \mu \mathrm{l}$ MS grade water on each Zeba column, and spin at 1,500 $\times \mathrm{g}, 2 \mathrm{~min}$. Put the column on another clean tube.

2. Mix $10 \mu \mathrm{l}$ protein and $1 \mu \mathrm{l}$ small molecule of a serial dilution (usually at least 10 dots to encompass 1,000 fold range) in tubes. 
3. Pipette mix and incubate at RT for $15 \mathrm{~min}$.

4. Transfer the mixture in each tube to a Zeba column, let sit 1 min. Then spin down.

5. Add $40 \mu \mathrm{l} \mathrm{MS}$ grade methanol to each tube, pipette mix and spin at maximal speed $5 \mathrm{~min}$ at $4{ }^{\circ} \mathrm{C}$.

6. Transfer the supernatant to a glass insert in a vial for mass spec analysis.

7. Each sample will be loaded 3 times, along with the serial standard solutions of the small molecule at final concentrations used in the binding mixture. Quantification is performed in LCQuan software or other appropriate software.

\section{References}

1. Li, X., Gianoulis, T. A., Yip, K. Y., Gerstein, M. and Snyder, M. (2010). Extensive in vivo metabolite-protein interactions revealed by large-scale systematic analyses. Cell 143(4): 639-650. 